\title{
The effects of flipped learning on learning motivation and attitudes in a class of college physical therapy students
}

\author{
Authors: \\ Eun Jung Chung ${ }^{1}$. Byoung-Hee Lee ${ }^{2}$ \\ ${ }^{1}$ Assistant Professor, Department of Physical Therapy, Andong Science College, Republic of Korea \\ ${ }^{2}$ Associate Professor, Department of Physical Therapy, Sahmyook University, Republic of Korea
}

\section{ABSTRACT}

Purpose: This study aims to verify the effects of flipped learning on learning motivation and attitudes in a class of college physical therapy students.

Methods: The subjects were 97 students in College A who had registered for musculoskeletal examination and assessment and practice at the second semester of 2017. The flipped learning program was applied to students for one semester, after which a paired t-test was performed to compare the dependent variables (learning motivation and attitudes) before and after the flipped learning program.

Results: The results showed significant differences in learning motivation (attention, relevance, confidence, satisfaction) and attitudes (attitude about physical therapy).

Conclusion: These results suggest that flipped learning improves learning motivation and attitudes. Therefore, follow-up study is necessary to investigate further the application of flipped learning in various students and teaching methods. 


\section{INTRODUCTION}

At present, human beings are facing the era of the "Fourth Industrial Revolution" due to unprecedented rapid technological innovation. The lightning-pace development in the fields of knowledge information is leading the fourth industrial revolution, including the development of artificial intelligence (AI), robotics, big data, nanotechnology and biotechnology. In particular, with the advent of the Fourth Industrial Revolution in which creativity, challenging spirit, and personality become important, there is widespread perception that previous system of education can no longer secure students' future, therefore, a new educational paradigm, which is completely different from existing education, is needed. Consequently, the revolutionary change in education that is in accord with the paradigm of a hyper-connected and ultra-intelligent society in the fourth Industrial Revolution era is urgently required (Schwab, 2016).

Due to these series of changes, non-traditional teaching methods have been introduced in the education system. Some of the key changes in the education paradigm of the twenty-first century include the shift from teacher-centered to student-centered instruction, from teacher-dominated and one-sided lecture to a dynamic model of teacherstudent interaction, from knowledge to capacity, from theory to practice, from principle and editorial to problem and question, from competition to collaboration, and from uniform learning to individual learning.

These teaching methods are presented as problems, one of which is the problem-based learning (PBL) method (Jung \& Kong, 2017; Kong, Qin, Zhou, Mou \& GAO, 2014). Team-based learning (TBL) is an agreement and cooperation between one or more teachers for the purpose of achieving common educational goals and carrying out teaching-related activities (Burgess, McGregor \&
Mellis, 2014), On the other hand, flipped learning is an instructional method that reverses the previous education method so that students listen to the lectures produced by teachers at home, and the teachers and students discuss at school to solve problems (Gopalan \& Klann, 2017).

In particular, flipped learning, unlike existing school study methods, is a convergence learning method that focuses on interaction in the form of problem-solving and discussion-based lessons after learning lessons at home online in advance, which can include a variety of individual classes and learner-centered activities such as projectoriented learning (Yoon, Park, \& McMillan, 2017; Jensen, Kummer \& Godoy, 2015).

The advantages of the flipped learning method include the following: (1) learners come to class prepared, with the same level of relevant information and knowledge, ready for application,-; (2) student engagement in activities is promoted through active learning sessions, as students spend in-class time applying knowledge and theory previously learnt,-; and (3) student motivation is increased, as they are accountable to each other for their contribution to activities (McLaughlin et. al., 2014).

Boucher et al. (2015) reported that implementation of the flipped classroom approach for instruction in the musculoskeletal curriculum of first-year physical therapist students produced positive feedback from both students and faculty. However, in the previous domestic studies on flipped learning, the application of flipped learning was studied in various subjects at different school levels: among elementary (Seo, 2017; Leem \& Kim, 2016; Lee, Kang \& Kim, 2015), middle school (Lim, Jin, Kim \& Jo, 2016; Kim \& Lim, 2016), and high school students (Lee \& Kim, 2017). In addition, various studies applying a flipped learning strategy have been conducted on university students using the instructional design model development or through 
a case study based on the flipped learning approach and there are many studies on nursing course (Choi, Kim, Bang, Park, Lee \& Kim, 2015; Geist, Larimore, Rawiszer \& Sager, 2015). However, few studies have been conducted to application in the field of physical therapy except for the Boucher (2013)'s study. Therefore, a study that verifies the effects of flipped learning in the field of physical therapy are needed can apply this method in their instruction. For that reason, this study aimed to verify the effects of flipped learning on learning motivation and attitudes in a class of college physical therapy students.

The objectives were to;

First, evaluate the learning motivation to investigate the effect after application of flipped learning.

Second, evaluate the learning attitudes to investigate the effect after application of flipped learning.

\section{METHODOLOGY}

\section{Design}

This study consisted of pretest-posttest design for one group of students.

The participants comprised 97 first year students of physical therapy at a college located in Gyeongbuk province. The dependent variables for this study are learning motivation and attitudes. The subject is a first grade topic, musculoskeletal examination and assessment, and practice. This subject is a course that entails learning the basics of joint range of motion measurement and muscle testing in physical therapy classes for first year students. The actual classes were conducted for a total of 18 hours, 3 hours per week for 6 out of 15 weeks. This study was approved by the Sahmyook University's institutional review board
(IRB 2017096HR). All subjects signed a written informed consent form prior to participation. The flow diagram of experimental procedure of this study is schematized as shown in Table 1.

Table 1. Flow diagram of experimental procedure

\begin{tabular}{|c|c|}
\hline Level 1 & Class design and video production \\
\hline Level 2 & Orientation for flipped learning \\
\hline Level 3 & Pre-test (learning motivation, learning attitude) \\
\hline Level 4 & Class for six weeks \\
\hline Level 5 & Post-test (learning motivation, learning attitude) \\
\hline Level 6 & Analysis of collected data \\
\hline
\end{tabular}

\section{Instructional design}

Based on the analysis of literature data and previous research (Kim, 2015), this study, divided the class process into Pre-Class, In-Class, and After-Class. The instructional design and activities using flipped learning are shown in Table 2. In the online lecture materials, one or two video lectures were produced for each lecture, and the lecture videos were made in PowerPonit and lasted about 15 minutes. The program used for making the lecture videos was Screencast-O-Matic (https://screencast-o-matic.com/) (Figure 1), and the production of the physical therapy practicing videos was DaumPotEncoder (typot. Daum.net/ application/PotEncoder.do) (Figure 2). 
Table 2. Instructional design and activities

\begin{tabular}{|c|c|c|}
\hline Topics & Contents & Activities \\
\hline $\begin{array}{l}\text { Understanding } \\
\text { assessment }\end{array}$ & - You can understand the record of evaluation & $\begin{array}{l}\text { - Pre-Class: watch videos } \\
\text { - In-Class: } \\
\text { 1. Q \& A } \\
\text { Quiz contents: Subjective, objective, assessment, and plan } \\
\text { (SOAP)notes (physical therapy recording paper) } \\
\text { 2. Group activity } \\
\text { Group activity contents: roles in group(patient, therapist) on } \\
\text { physical therapy record } \\
\text { - After-Class: class contents and group presentation sharing }\end{array}$ \\
\hline $\begin{array}{l}\text { Measuring the range } \\
\text { of joint motion }\end{array}$ & $\begin{array}{l}\text { - You can understand the kinds of range of joint } \\
\text { motion } \\
\text { - You can understand the testing method of the } \\
\text { range of joint motion }\end{array}$ & $\begin{array}{l}\text { - Pre-Class: watch videos } \\
\text { - In-Class: } \\
\text { 1. Q \& A } \\
\text { Quiz contents: differences of passive and active range of joint } \\
\text { motion } \\
\text { 2. Group activity } \\
\text { Group activity contents: roles in group(patient, therapist) on } \\
\text { the measurement exercise of the range of motion (by joint) } \\
\text { - After-Class: class contents and group presentation sharing }\end{array}$ \\
\hline Muscle testing & $\begin{array}{l}\text { - You can understand manual muscle testing } \\
\text { - You can understand the muscle testing of } \\
\text { upper extremity } \\
\text { - You can understand the muscle testing of } \\
\text { lower extremity }\end{array}$ & $\begin{array}{l}\text { - Pre-Class: watch videos } \\
\text { - In-Class: } \\
\text { 1. Q \& A } \\
\text { Quiz contents: manual muscle testing } \\
\text { 2. Group activity } \\
\text { Group activity contents: roles in group(patient, therapist) on } \\
\text { muscle testing (by joint) } \\
\text { - After-Class: class contents and group presentation sharing }\end{array}$ \\
\hline
\end{tabular}

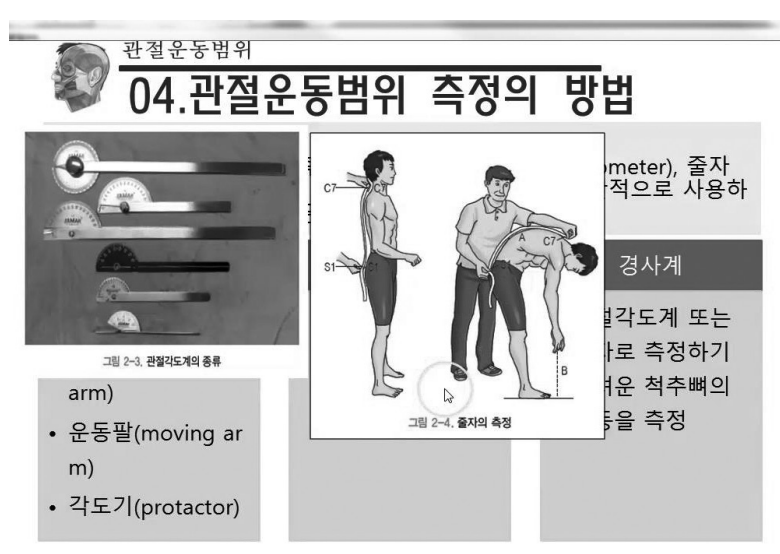

Figure 1. Sample of a lecture video

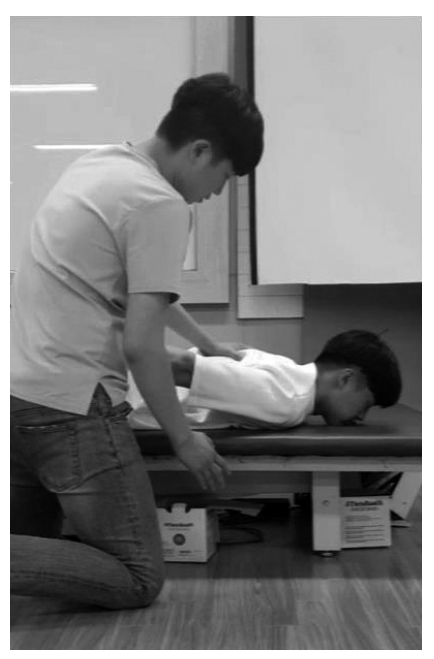

Figure 2. Sample of a video demonstration physical therapy practice 


\section{Instrument}

Learning motivation was measured using a modified form of the learning motivation test tool developed by Keller (1987). The learning motivation questionnaire consisted of 34 items. The levels of agreement ranged from "strongly disagree" (score of "1") to "strongly agree" (score of " 5 "). This means that the minimum score is 34 , whereas the maximum score is 170 , and the average score is 102 . The minimum, maximum, and average scores for each subscale can be different because of the different number of subcategories. The reliability of this study was Cronbach $\alpha=.916$ for the pre-test and $\alpha=.877$ for the post-test.

Learning attitudes subscales were used by the Korea Educational Development Institute (1992) to investigate the effect of flipped learning on learning attitude (Kim, 2015). The questionnaire consisted of 40 items, with 10 items on self-concepts about physical therapy, 15 on attitudes about physical therapy, and 15 on learning habits about physical therapy. The questionnaire used a standard 5-point Likert scale. The reliability of this study was Cronbach $\alpha=.939$.

\section{Statistical analysis}

All statistical analyses were performed using SPSS, version 21.0 (IBM SPSS Statistics; IBM Corporation, Armonk, NY, USA) and descriptive statistic was applied to results of the demographics. The internal consistency reliability used Cronbach's alpha and a paired sample t-test was used for the assessment of the differences between the pre-test and post-test sessions. The significance threshold was set to $p<0.05$.

\section{RESULTS}

The comparative results of learning motivation after flipped learning are shown in Table 3. Learning motivation showed significant differences $(p<.001)$. In addition, attention $(p<.001)$, relevance $(p=.002)$, confidence $(p<.001)$ and satisfaction $(p=.022)$ of learning motivation also showed significant differences.

Table 3. Comparison of learning motivation after flipped learning

( $N=97)$

\begin{tabular}{|c|c|c|c|c|}
\hline Variables & Pre-test & Post-test & $\begin{array}{c}\text { Mean } \\
\text { difference }\end{array}$ & $\mathrm{t}(p)$ \\
\hline $\begin{array}{l}\text { Learning } \\
\text { motivation }\end{array}$ & $3.39 \pm .37$ & $3.59 \pm .34$ & $-.20 \pm .50$ & $-3.916(<.001)$ \\
\hline Attention & $3.29 \pm .41$ & $3.51 \pm .38$ & $-.23 \pm .58$ & $-3.851(<.001)$ \\
\hline Relevance & $3.60 \pm .42$ & $3.80 \pm .39$ & $-.19 \pm .58$ & $-3.428(.002)$ \\
\hline Confidence & $3.31 \pm .42$ & $3.54 \pm .38$ & $-.24 \pm .55$ & $-4.271(<.001)$ \\
\hline Satisfaction & $3.34 \pm .44$ & $3.50 \pm .46$ & $-.15 \pm .65$ & $-2.322(.022)$ \\
\hline
\end{tabular}

The comparative results of learning attitudes after flipped learning are shown in Table 4. Learning attitudes showed no significant differences $(p=.162)$. In the subscale of learning attitudes, only significant difference was observed was in attitude about physical therapy $(p=.049)$.

Table 4. Comparison of learning attitudes after flipped learning

( $N=97)$

\begin{tabular}{|c|c|c|c|c|}
\hline Variables & Pre-test & Post-test & $\begin{array}{c}\text { Mean } \\
\text { difference }\end{array}$ & $\mathrm{t}(p)$ \\
\hline Learning attitude & $3.30 \pm .44$ & $3.39 \pm .42$ & $-.09 \pm .62$ & $-1.408(.162)$ \\
\hline $\begin{array}{l}\text { Self-concept about } \\
\text { physical therapy }\end{array}$ & $3.11 \pm .49$ & $3.20 \pm .48$ & $-.04 \pm .71$ & $-.586(.559)$ \\
\hline $\begin{array}{l}\text { Attitude about } \\
\text { physical therapy }\end{array}$ & $3.53 \pm .53$ & $3.67 \pm .48$ & $-1.4 \pm .69$ & $-.1990(.049)$ \\
\hline $\begin{array}{l}\text { Learning habit about } \\
\text { physical therapy }\end{array}$ & $3.19 \pm .45$ & $3.26 \pm .44$ & $-.07 \pm .67$ & $-.990(.325)$ \\
\hline
\end{tabular}




\section{DISCUSSION}

The flipped classroom can be defined as a set of pedagogical approaches that create the following (Abeysekera \& Dawson, 2015):

1. Move most information-transmission teaching out of class

2. Use class time for learning activities that are active and social

3. Require students to complete pre-and/or post-class activities to fully benefit from in-class work.

These findings are in line with the aim of this study, which was to examine the effects of physical therapy classes using flipped learning on the learning motivation and attitudes of college students.

Tang el al. (2017) investigated the effectiveness and acceptability of the flipped classroom approach to teaching ophthalmology at the clerkship level. Their study found that, more students in the flipped group agreed that the classroom helped to promote their learning motivation, improve their understanding of the course materials, and enhance their communication skills and clinical thinking. Although the measurement tools differ from this study, van Vliet et al. (2015) reported that flippedclass pedagogy enhanced the motivation strategies for learning questionnaire components of critical thinking, task value, and peer learning. The results of this study showed significant differences in learning motivation (attention, relevance, confidence, and satisfaction). This finding suggests that the flipped learning class enabled students to learn the concepts in advance, solve problems through group activities that were further deepened in class, and share the results; therefore, the attitude of active participation in class had a positive impact on learning motivation. Learning motivation not only induces learning but also maintains learning activities and informs the direction of learning. This learning motivation exists when students actively perform their class activities. It suggests that flipped learning has a positive effect on learning motivation because the curriculum and interest of the learners are increased due to the new teaching method and the design of the lesson is focused on the student.

In this study, learning attitude subscales were used by the Korea Educational Development Institute (1992) to investigate the effect of flipped learning on learning attitude. The results of this study, found no significant differences $(p=.162)$ in the total learning attitudes.

Hsu et al. (2016) showed that the flipped classroom can indeed change the postgraduate student's learning followed by attitude ( $\mathrm{r}=0.365, p=.01)$. Rui et al. (2015) reported that students in a flipped learning group scored significantly higher than in a lecture-based learning (LBL) group on electrocardiogram interpretation. The vast majority of students in the flipped classroom group held positive attitudes toward the flipped classroom method, but they also supported LBL.

In this study, the subscales of self-concept and learning habit showed no significant differences. The 'self-concept' about physical therapy in learning attitude, there was no significant difference in these items such as "I seem to be good at physical therapy" and "I am good at physical therapy" because subjects are a first-year student who first studies physical therapy. However, in learning attitudes, the only significant difference was observed in the subscale attitude about physical therapy $(p=.049)$. The reason for the difference in the only learning attitude subscale is that the students with sufficient prior learning (in-class video lecture) can participate positively in the class regardless of their learning level, and the process of team work with 
classmates is regarded to positively change the attitude of students towards the subject together with feedback from peer learners and professors. In addition, this study did not compare the differences of learning attitudes according to the learning level (without dividing into low proficiency students and high proficiency students); instead, it was conducted on all students. As the individual learning of the more proficient learners was not considered in the flipped learning class, the subscales of self-concept and learning habit showed significant differences.

This study has several limitations. First, there is no control subject in this study. In follow-up study, need to study a comparison between traditional teaching method and flipped learning teaching method. Second, there is not consider the learning level in subjects. Therefore, follow-up research needs to compare the effects of flipped learning according to students' learning level (low proficiency students and high proficiency students) and the effects of the traditional teaching method with the flipped learning method.

\section{CONCLUSION}

This study examined the flipped learning approach, and results of the analysis conducted found that flipped learning improves learning motivation and attitudes. It is necessary to study the application of flipped learning in different groups of students and other teaching methods in a follow-up study.

\section{REFERENCES}

Abeysekera, L., \& Dawson, P. (2015). Motivation and cognitive load in the flipped classroom: definition, ratlonale and a call for research. Higher Education
Research \& Development, 34, 1-14.

Boucher, B., Robertson, E., Wainner, R., \& Sanders, B. (2013). "Flipping” Texas State University's physical therapist musculoskeletal curriculum: implementation of a hybrid learning model. J Phys Ther Educ, 27(3), 72-77.

Burgess, A. W., McGregor, D. M., \& Mellis, C. M. (2014). Applying established guidelines to team-based learning programs in medical schools: a systematic review. Academic medicine, 89(4), 678-88.

Choi, H., Kim, J., Bang, K. S., Park, Y. H., Lee, N. J., \& Kim, C. (2015). Applying the flipped learning model to an English medium nursing course. J Koren Acad Nurs, 45(6), 939-948.

DaumPotEncoder. typot. Daum.net / application / PotEncoder.do

Geist, M. J., Larimore, D., Rawiszer, H., \& Sager, A. W. A. (2015). Flipped versus traditional instruction and achievement in a baccalaureate nursing. Nurs Educ Perspect., 36(2), 114-115.

Gopalan, C., \& Klann, M. C. (2017). The effect of flipped teaching combined with modified team-based learning on student performance in physiology. Advances in physiology education, 41(3), 363-367.

Hsu, S. D., Chen, C. J., Chang, W. K., \& Hu, Y. J. (2016). An Investigation of the outcomes of PGY student's cognition of and persistent behavior in learning through the intervention of the flipped classroom in Taiwan. PloS one, 11(12).

Jensen, J. L., Kummer, T. A., \& d M Godoy, P. D. (2015). Improvements from a flipped classroom may simply be the fruits of active learning. CBE life sciences education. 14(1), ar5. Doi: 10.1187/cbe. 14-D8-0129.

Jung, E. Y., \& Kong, J. H. (2017). The development and effect of CPBL (Creative Problem Based Learning) for nursing student. J Probl Based Learn, 4(1), 5-14. 
Keller, J. M. (1987). Development and use of the ARCS model of instructional design. Journal of Instructional Development, 10(3), 2-10.

Kim, E. J. (2015). The effect of flipped learning strategy on motivation, academic achievement, and self-directed learning of junior college students. Major in Educational Technology Incheon National University.

Kim, S. W., \& Lim, K. Y. (2016). Relationships among selfregulation, teaching presence, perceived interaction, and learning outcomes in a flipped learning environment: Mediating effects of perceived interaction. The Korean Association of Eductional Methodoogy Studies, 28(4), 743-766.

Kong, L. N., Qin, B., Zhou, Y. Q., Mou, S. Y., \& Gao, H. M. (2014). The effectiveness of problem-based learning on development of nursing students' critical thinking: a systematic review and meta-analysis. International Journal of Nursing Studies, 51(2), 458-469.

Korea Development Institute. (1992). A study on evaluation system of mathematics education for pursuit of the exxence od education. Seoul: Korea Development Institute.

Lee, H. S., Kang, S. C., \& Kim, C. S. (2015). A study on the effect of flipped learning on learning motivation and academic achievement. The Journal of Korean association of computer education, 18(2), 47-57.

Lee, T. K., \& Kim, J. Y. (2017). Development of PE classes applying flipped learning strategies: Based on sportscasting model. Korean Journal of Sport Science, 28(2), 440-460.

Leem, J. H., \& Kim, S. H. (2016). Effects of flipped learning on learning achievement, collaboration ability, and ICT literacy in smart learning environment. Journal of Educational Technology, 32(4), 809-836.

Lim, K. Y., Jin, M., \& Kim, S. W. (2016). Relationships among self-determination, collaboration preference, cognitive and perceived achievement in flipped learning environment. Korean Association for Education Information and Media, 22(3), 439-462.

McLaughlin,J.E., Roth,M. T., Glatt,D.M., Gharkholonarehe, N., Davidson, C. A., Griffin, L. M., Esserman, D. A., \& Mumper, R. J. (2014). The flipped classroom: a course redesign to foster learning and engagement in a health professions school. Academic medicine: journal of the Association of American Medical Colleges, 89(2), 236243.

Rui, Z., Lian-Rui, X., Rong-Zheng, Y., Jing, Z., XueHong, W., \& Chuan, Z. (2017). Friend or foe? Flipped classroom for undergraduate electrocardiogram learning: a randomized controlled study. BMC Medical education, 17(1), 53.

Schwab, K. (2016). The fourth industrial revolution. Geneva, Switzerland; World Economic Forum.

Screencast-O-Matic. https://screencast-o-matic.com/

Seo, J. Y. (2017). An action research on classting-based flipped learning in elementary school social studies class. Journal of Qualitative Inquiry, 3(1), 217-255.

Tang, F., Chen, C., Zhu, Y., Zuo, C., Zhong, Y., Wang, N., Zhou, L., Zou, Y., \& Liang, D. (2017). Comparison between flipped classroom and lecture-based classroom in ophthalmology clerkship. Medical education online, 22(1), 1395679.

Yoon, S., Park, M. Y., \& McMillan, M. (2017). An illuminative evaluation: student experience of flipped learning using online contents. J Probl Based Learn, 4(1), 47-54.

van Vlient, E. A., Winnips, J. C., \& Brouwer, N. (2015). Flipped-class pedagogy enhances student metacognition and collaborative-learning strategies in higher education but effect does not persist. CBE life science education, 14(3), ar26. 